\title{
Fistula Discharge
}

National Cancer Institute

\section{Source}

National Cancer Institute. Fistula Discharge. NCI Thesaurus. Code C122470.

The leakage of a substance from a fistula. 